\title{
Social Disorder as a Social Good
}

\author{
Jonathan Marshall \\ University of Technology, Sydney
}

\begin{abstract}
In complex systems, disorder and order are interrelated, so that disorder can be an inevitable consequence of ordering. Often this disorder can be disruptive, but sometimes it can be beneficial. Different social groups will argue over what they consider to be disordered, so that naming of something as 'disorder' is often a political action. However, although people may not agree on what disorder is, almost everyone agrees that it is bad. This primarily theoretical sketch explores the inevitability and usefulness of disorder arising from ordering systems and argues that a representative democracy has to tolerate disorder so as to function.
\end{abstract}

\section{Introduction}

Much talk in political life suggests government waste or inefficiency is bad, duplication is bad, the number of politicians should be reduced, the number of tiers of government should be slashed, bureaucracies should be reduced and so on. In general it is assumed that, better, leaner, more efficient organisation, management, measurement or regulation, solves problems.

The 2020 conference (2020 Plenary Stream Report) called for: 'Performance targets' (p.5), 'urgent action to increase economic capacity through the creation of a truly national, efficient, sustainable, innovative and inclusive economy supported by seamless regulation' (p.8); ‘efficient regulation’ (p.9); ‘Regulation reform to reduce regulation overlaps and complexity and to incentivise timely investment in infrastructure' (p.10); 'An integrated, whole-of-government approach underpinned by clear targets and measurement with independent reporting’ (p.21); ‘uniform regulation’ (p.33), 'Nationwide harmonisation of regulation, standards and enforcement' (p.34) etc.

Slightly later, prominent conservative politician, and now leader of the opposition, Tony Abbot was reported as announcing that: 
'The biggest problem Australia faces today is the dysfunctional Federation... It's absolutely critical that we establish who's in charge of all areas of governance.

'I will be arguing for a constitutional amendment to establish that, where it so wishes, the Commonwealth can pass laws to override the states - not just Section 51 as it is now, but in all areas...

'The federal government is totally hamstrung by the legal authority that resides in the states....

The article went on to claim that:

There is considerable bipartisan federal impatience with the incompetence and intransigence of the states. Last week, the Defence Minister, Joel Fitzgibbon, proposed abolishing the states altogether, an idea Mr Abbott described as impractical (SMH: 10 July 2008).

The ex-treasurer of NSW, Michael Costa also called for the abolition of the States saying, 'it would remove a layer of political interference in service delivery’ (SMH 13 Sept 2008). A website for a group calling itself Australia 100 protested against 'Duplicated Bureaucracies and Regulatory Regimes', 'Excessive parliamentarians' and so on. Others (e.g. Cole and Parston 2006) call for 'measured outcomes' and 'informed decisions' (as if many people had campaigned on behalf of uninformed decisions). It is easy to find further examples, from all sides of politics, all calling for efficient organisation with a smooth flow of power.

Although the 2020 conference emphasised 'inclusion' and 'Rights' in most of its panels, there was no consideration of whether such 'inclusion' or 'Rights' was compatible with these demands for efficiency.

There is little criticism of this praise of order from social and political theory. From Bodin and Hobbes onwards the spectre of social disorder has been used to justify order of almost any type; in their case, order which can overwhelm claims of justice or 'Rights' (King 1974). Marx seems to have thought disorder and serious conflict would stop with the revolution. Durkheim thought anomie, or social disorder, to blame for suicide, and sought to prevent disorder in general, although he was happy to consider some forms of disorder (such as crime) as normal if the rituals around it restated the importance of order (Durkheim 2006; Marks 1974). Max Weber argued that we should construct unambiguous 'ideal types' to do our analysis, thus deleting disorder by ignoring it (Whimster 2004, pp.387ff.). Even Anarchists talk about spontaneous order, and rarely celebrate disorder itself: Proudhon supposedly declared that 'anarchy is order' (P.Marshall 1992, p. x). An obvious advantage of 
focusing on order is that it helps to remove from our perception, those parts of social life that cannot be explained by the theory being proposed.

However, what if disorder arises from ordering or if disorder is sometimes beneficial? If either of these possibilities are allowed, then we can challenge the notion that if something is not working then it must be in need of greater organisation. It might already be too organised, or organised according to inappropriate principles, or the ordering may have side effects. Perhaps redundancy, waste, disorder and frictions, provide the time and place to object, to slow things down, to circumvent rules, thus allowing Civil Society to function? If so, then it may be necessary to distinguish between creative, or functional, disorder on the one side and disruptive disorder on the other.

To avoid confusion let me state what this paper is not arguing. Firstly I am not denying that social disorder can impinge negatively upon 'human rights', or that disorder, ambiguity or incoherency cannot be exploited to maintain an oppressive order (see for example Ferrara 2003). All disorder is not the same.

Secondly I am not defending the order of corporate markets. The order of capitalism or markets is not under-regulated. The supposedly freer the market, the more protection and regulation the corporate sector has in their favour - such as copyright ownership; skewed distributions of income from work; rewards for failed executives; regulation of workers; diminution of responsibility for working conditions; regulation of unions, strikes or protests; shifting tax burdens onto the middle class; government transfer of taxpayer monies to the corporate sector through contracting or asset sales; shifting of responsibility for regulation onto the industries being regulated, and so on. Even if capitalism was anarchic, then by encouraging huge divergences of wealth and power it creates an elite who will attempt to organise the State to prevent others from impinging on their rights and power. Political ordering is part of the corporate market, not extraneous to it.

This paper does argue that:

i) a certain amount of disorder and inefficiency is not only an inevitable consequence of organisation itself, but that

ii) disorder can be beneficial to civil society and to democracy. 
In particular the paper proceeds by showing how ordering can create disorder through necessary technologies of ordering such as: categorisation, communication, disruptive reflexivity, and administration.

\section{On ordering}

Whatever the ordering system, only a relatively narrow band of events can be classed as ordered, while an infinite range of events can be classed as disordered. As a result 'disorder' seems much more common than 'order' (Bateson 1972, pp.3-8). The greater the precision demanded in the order, the greater the range of events which will appear disordering. Think of arranging objects on a tray. An obsessive person may demand that each object has a precise place so that even a millimetre displaced represents chaos, while a less demanding person may have a greater range of acceptable positions for the objects, and thus face less chaos and distress. Both of these hypothetical people might think that the other person's arrangement was disordered, even if they had its purpose and method explained to them. This explaining might then lead to conflict as they realise their fundamental incompatibility, causing a further crisis of order as they try to assert their own order.

Orderers tend to see what they classify as disorder as bad; as falling outside the categories they use to classify and order the world, unless it is to be classified as evil or threatening (cf Douglas 1966). They have a discomfort with ambiguity as well as disorder. This means that ordering is often incompatible with a politics which is not merely confirmatory of existing schemas, and is thus ineffective in situations of change, as change is categorised as threat or disorder. But being able to do what was done before would imply the situation was the same as previously, even though no situation is ever exactly the same as previously, only similar. What makes something similar, is itself an active ordering or categorising response which invokes the possibility of acting on the event similarly with similar success. In that sense, similarity is circular and precarious; as we only discover the situation is not similar enough when the ordering fails.

\section{Technologies of Ordering}

Order is frequently associated with what we might call 'technologies of ordering': classificatory systems, filing cabinets, command structures, divisions of labour, methods and structures of communication, arrangements of space, barriers, etiquette, maps, shelving and so on. As an example, we may think of the way government attempts to order people so as to: 
allocate rights, responsibilities and obligations; to provide services to those it considers worthy and refuse services to those not fitting that classification; or to decide who is a full member or citizen and who is not etc. It also aims to categorise its workers/administrators, so they can act and be controlled in that act. Computers and software are the tools commonly used nowadays to classify people, which leads to a whole set of problems in itself. We all know the excuse that 'the computer will not let me do that' and, as another example, computers also allow automated customer help call waiting 'services', which more efficiently parcel labour for the organisers, with the result that things often remain done incorrectly or remain undone.

It is characteristic of all technologies that they both enable and restrict - not just one or the other. A filing cabinet, for example, puts everything partially out of reach, usually in an ultimately arbitrary order; documents can get lost in the cabinet, it might not be clear how the documents are classified, and documents usually have to be removed from the system to be useful, a pool of disordered documents usually accumulates before they go back into the filing system and so on. The potential for disorder allows the technology to function as well as fail.

A technology, by definition, is something which simplifies and which excludes parts of the complexity of reality, in order to magnify other effects. Technology tends to both cut off unseen connections, and to make unseen connections. Technology:

consists in substituting a man-devised organisation of matter, the 'technosphere', which is relatively crude and geared to the satisfaction of short-term anthropocentric ends for the 'biosphere' remarkable for its subtlety and geared to the maintenance of long-term stability (Goldsmith 1973,p. x) ${ }^{1}$.

The relatively old book from which this remark comes, describes the unexpected and disruptive effects of technology on 'natural systems'. Such events might be summarised (itself an ordering which deletes), as eventuating when 'linear' or 'discrete unit' based technology encounters a complex 'cybernetic process' or 'flow'. The world is in some sense always in flux and always messy, with imperceptible links and complex consequences, and thus it escapes or resists attempts to render it linear, and break it into discrete units. Forcing

\footnotetext{
${ }^{1}$ Today we might be less certain about the stability of the biosphere. It also undergoes constant change, and biological adaptation can subvert the aims of the technology as when bacteria become resistant to antibiotics and cleaning agents.
} 
the world into linearality, or putting it under rules, can render the system unworkable, or lead it to work in unexpected ways, producing further disruption.

As everything is constantly changing, technologies of ordering are all impermanent. Organisation always lags, and must always lag and hence be inaccurate, otherwise organisation does not provide a simplification that enables people to act. If the technology of ordering is maintained in the face of massive change then the ordering body will gradually even more lose touch with the reality.

\section{Rules}

The most obvious organisational technology is the rulebook, aiming to make things predictable, and events similar. As businessman Ricardo Semler writes: 'In their quest for law, order, stability and predictability, corporations make rules for every conceivable contingency' (1992, p.96), but rules can slow things down as well as speed things up - people spend hours arguing about how they should be interpreted, and about the situations they are being applied in, or they ignore the specifics in favour of the rule. As well as clarifying procedures, rules create distrust because they imply that people in the organisation cannot be trusted, and yet they have to be trusted. Rules divert attention from the organisations' objectives, create extra work for rules checkers, fossilise behaviour which may no longer be appropriate, making development difficult, and direct people's effort to creative rule bending, so that the organisation can work. Rules are necessary for order but create disorder.

Law and the legal system could be a development of the rulebook, and ideally acts as a protection against arbitrary power, or at least clothes official violence in ritual and respectability. The legal system is precisely, a linear technology imposed on the complexities of social life. In practice, Western law avoids some of the resultant dilemmas by being situational, although pretending to be universal. Judges and juries steer their ways through strange intricacies which are often deleted when the decisions are reported with indignation in a couple of paragraphs, or seconds, in the media. Often those who consider themselves 'popular opinion' want simple rules applied uniformly, except when it comes to themselves, when the complications previously ignored become obvious ${ }^{2}$. At other times the law is

\footnotetext{
${ }^{2}$ Conservative newspaper columnist Miranda Divine, for example, frequently castigates judges and politicians for letting criminals go, while being indignant about suffering from the speeding laws which apply to her.
} 
applied rigorously and that can also seem to be a form of blindness or disruption. However, in general, the legal set-up recognises that what is the correct procedure in one situation may not be so in another situation which appears similar. The problem consists in deciding what is 'the same'. Rather than assuming that similarity automatically comes to the fore, people in the law deal with this problem through argument, and through attempts 'to get away with things ${ }^{3}$. Those in the law, in effect, attempt to break the laws they are enforcing. This can lead to the legal system allowing people to render their responsibility opaque and sever the ties that the law supposedly reinforces. This is particularly marked in cases like Mabo, where the appropriating authority is trying to deal with the appropriation of the land that gives it its own legitimacy and force (Veitch 2007, especially pp.100ff.).

However, the law often has to be contradictory in order to be fair. Despite the presumption of innocence, courts do not release all charged people before their trial, and sometimes this results in innocent people serving time in jail. Sometimes the accuser will be protected at the expense of the accused in an attempt to stop victims from being further traumatised (despite this assuming the guilt of the accused). Such problems cannot be avoided, and the fairer the situation the more such problems may arise. Incoherence may allow fairness as well as corruption - and fairness is not straightforward, as guilt, innocence and responsibility are not known in advance.

Furthermore, it may never be possible to cover all possible cases, in all changing circumstances, by strict laws specified in advance, and if we attempt to do so then the system becomes a game of rules not 'Justice' and the system loses credibility.

\section{Categorisation}

Understandings and theories act as filters and selectors of events from the overwhelming flux of reality (Popper 1972, pp. 341ff.; Feyerabend 1999). Conceptual tools are a technology of ordering.

\footnotetext{
${ }^{3}$ This situational law or justice would seem to undermine the Kantian categorical imperative (where moral action is independent of conditions and desires and each person ought to do what everyone should do in a similar situation) as, if the disorder is taken seriously, then it implies that staying with Kant's order would render life impossible - a point made by one of Kant's translators, although he does not think it undermines the theory in principle (Abbot 2005, pp.13ff).
} 
Dividing the world into categories is a way of simplifying the world and of gathering things and events together which are different - there is rarely a category of one thing ${ }^{4}$.

Furthermore, humans do not, in general, categorise things and events in the classic Platonic manner by making a definition so that all things in the category are the same in the same way. Often, those things or events which belong in a category are placed in it in varied ways. They can be linked to a central item or prototype, being similar to it in different ways; they can be linked in chains in which distant members have very little in common and so on. Linkages can be influenced by the needs the users wish them to serve, the feelings users have about the categorised, or the ways the categorised fit in with other categorisations (as membership of a category is influenced by comparison with the other categories being deployed at the same time). Many or most categories will be ‘congeries' or 'collections' rather than definitional. They, or their members, will also be subject to argument - 'is that person a refugee, a resident alien, an overstaying tourist, or an economic migrant', 'do we have a class society' etc. Membership in a category, and the category itself, almost always has the possibility of being challenged.

Locating somebody in a category will give you some valid information about that person, but not everything the category implies is accurate. Thus because someone is a woman does not necessarily mean she is mathematics phobic or that she likes young children. The average man may be shorter than the average woman, but that tells us nothing about a particular woman and man. A person will only share certain interests or properties with other people of the same category, and this can be cut through by other categories, such as class. An upper class woman may have more interests and properties in common with an upper class man than with her cleaning woman. People tend to spill out of categories, and thus categories can be misleading, even if necessary.

Categories also create difference. Let us suppose we use religion as a primary classifier for people, then some people will be classified as belonging to religion $\mathrm{X}$ in relation to religion $\mathrm{Y}$ whether they particularly identify with religion $\mathrm{X}$ or not. Classification includes them in previous histories and rivalries, it forces people to emphasise a part of themselves, joins them with others they may want to break from, and allows others to treat them as defined by that

\footnotetext{
${ }^{4}$ I have discussed the issues mentioned in this paragraph at length in Marshall (2006, 2007).
} 
religion alone. This may then be enforced by violence. By replacing the mess of human actuality with sharp categories more tension and disorder can be created.

It can be even more disordering to administer through computer programs which classify people in advance of the program being written. At least human categories have the possibility of ongoing change should they prove inadequate to the reality encountered, whereas computer categories cannot be altered without a great deal of work, which will probably not be done due to expense and inertia. The more rigorous and stable the demand for categorisation the greater the chance that categorisation will be misleading.

People must categorise, so avoiding this problem of category-created chaos is impossible, but we can be more aware of it, or less aware of it, and more or less willing to alter our categories to fit with reality. Conceptual schemes are inevitably skewed and disordered with respect to reality and this is increased when they become the basis of communication - as one effect of categorisation is that 'who' a person is classified as will affect the way that their message is interpreted, and thus their intentions may be completely overwritten by their listener's sense of appropriate order.

\section{Communication}

Communication while increasing the possibility of order is also disordered by order. Good communication is only possible between equals (Wilson 1980, pp.118-25) ${ }^{5}$. If punishment is possible then a person will adjust the message towards what they think the potential punisher wishes to hear. After several levels of hierarchy, and the same process, the message can be distorted beyond recognition. This is one basis of the power/stupidity nexus. However, if there is no punishment for bad messages then there is no guarantee that the messages will be accurate either, as it may still serve the interest of those below to be inaccurate.

Hierarchy embodies secrecy and bad communication. Secrecy can be a resource used by managers to imply that they have access to a source of mysterious power or understanding, and it allows managers to protect their status by hiding mistakes. However, those beneath can simply assume the worst, and start a counter-secret chain of rumour which fills in the gaps

\footnotetext{
${ }^{5}$ It shows the disreputability of disorder as a topic for theorisation, that many of the best generalisations about disorder in administration come from supposedly comic writing such as Wilson (1980), Parkinson (1958), Peter \& Hull (1969), Adams (1996), and Haga \& Acocella (1980).
} 
and becomes the perceived truth of the organisation - again a 'truth' which is rarely reported upwards.

Increasing the amount of communication does not mean that people will be better informed, as they can then start skipping messages to get to the ones they already know might be good or useful. The more information is available, the easier it is to select information that agrees with one's previous biases ${ }^{6}$. A related difficulty arises because redundancy helps a message to get through, or a meaning to occur - it allows people to reduce the ambiguity of words and symbols. Without redundancy and excess, the only way to ensure stability of meaning is through force or the suppression of noise (i.e. the unexpected or irrelevant), but if a message seems entirely noise free, expected or predictable then it has little information (Hayles 1989, p. 306). Attempts to reduce noise, such as spam filters in email, can then remove important messages that fit the way that spam is recognised. So redundancy threatens messages, as does removing it.

Communication, in itself, does not always bring harmony, or solve the problems of social disorder, as it can propel people who disagree into conflict and it is harder to hate someone you don’t know exists (Marshall 2002). Consultation may even make people feel snubbed if they do not achieve what they hoped for, thus producing further alienation, or pushing people to silence or to hiding behind the noisy few who do get distributed and heard.

Good communication takes time, toleration of misunderstanding, working out of difference and so on, and is thus inefficient. As communication consumes time, it also renders complete accuracy impossible in a complex and shifting situation. Hopes for complete accuracy and efficiency are simply disordering.

\section{Reflexivities}

A further consequence of these problems with communication is that social processes always combine order and disorder because of what we might call 'multiple interactive reflexivities'. This simply means that everyone has some understanding of how the world works, how to interpret others, and how to operate within that world. Even the best attempts to render these

\footnotetext{
${ }^{6}$ This is a kind of Gresham's law of information; 'bad information drives out good'. Ungar suggests we live in a 'knowledge aversive culture' rather than a 'knowledge society' (2003). See also the idea of Agnotology, the study of culturally induced ignorance (Proctor \& Schiebinger 2008).
} 
understandings uniform, comes up against errors of transmission and replication. As a result there is always a complex divergence of views, interpretations of message and events and responses to those messages and events. Further, these reflexivities do not exist alone, but interact and modify each other. People are generally aware that other people are likewise operating according to some views and thus some, at least, will attempt to second guess, anticipate, help or avoid, the actions of others and the results of those actions. Thus even when there is general agreement and order, people will attempt to manipulate or subvert the results of those actions and orders. If people attempt to predict the actions of other people then that changes the situation, and this gets progressively more complicated, producing the kind of 'fog' that Clauswitz described of war (Beyerchen 1992-93).

Post chaos theory and Lorenz's butterfly effect, we can no longer be certain that the complex web of interaction between these different reflexivities will even-out into an 'average' response or into a predictable equilibrium (Eigenauer 1993, p.458). Therefore as what others will do, or the consequences of what they do, is never entirely predictable (especially when modified by the effects of other's responses), disorder is always potentially present (Merton 1936).

One way of explicitly allowing the web of reflexivities into politics, is to allow or encourage the development of institutional bases for some of these knowledges and resistances to occur. Instead of aiming to oil away friction, the aim would be to allow the frictions to collect and to give them a semi-permanent basis for action. This goes against the general 'cutting away of inefficiencies’ paradigm. However, even then, this ordering process is undermined by the time it takes to hear all the different views, never mind understand them or find a way of comparing them. It may, like consultation, even emphasise the knowledge that some people are not heard. Whatever the procedure, not everyone can be heard, and accepting the majority opinion does not really make sure that that majority is correct, or that it will not affect minorities adversely. While exclusion creates disorder, so does inclusion.

\section{Creativity and Problem Solving}

Creativity is inherent in almost any system that responds to the world and includes the world as an input/output. However, because it is driven by problems or sometimes by the random coming together of different ideas so as to form something new which allows a progression, creativity can be hampered by order. Order can prevent the new problems becoming 
apparent, can resist solutions to the problems that challenge its ordering, and can hinder the coming together of random ideas. Order can also prevent the transmission of ideas as when people decide not to tell those higher in the organisation of a potential solution because they know it might be rejected and they would lose status by being associated with it. Order may not allow creativity in the sense of giving it the freedom, or wasted time, to develop an idea, as ideas are nearly always weak when first proposed and thus easily destroyed. Order may selectively store the memory both of previous failures and of previous successes that have resulted from following the path of order, and thus decide that creativity or the creative node/person is a failure. People engaged in ordering can also see creativity as a form of vandalism, of defacing its idols, and thus attempt to crush anything which ruins its treasured tidiness (Peckham 1979, pp. 274ff.).

While people who operate within systems dominated by technologies of ordering are efficient at solving problems through moving symbols around in accordance with the official rules for symbol manipulation (say solving problems within a system, or framework, of established mathematics), they may not be so good at changing the meaning of symbols, changing the framework, or of opening new categories (so as to make a new branch of mathematics). The latter process involves changing modes of being or perceiving, and changing the ways that things will be done; and sometimes solving problems does need a complete shift of framework. This distinction resembles the one Samuel makes between 'Priests' and 'Shamans' (1990, pp.106ff.). Priests work within the world of order; Shamans attempt to make a new world. What does seem probable is that both of these seemingly opposed kinds of approach are actually needed. The priests develop the discovery, and in so doing lead the shamans to a new take off point, for a new development, which is then explored completely and rigorously by the Priests. While Shamans might innovate a completely unreal or maladaptive system, Priests are rational administrators, but as we will see in the next section rational administration can also disrupt itself.

What seems likely is that when the power system and the ordering systems are matched, then it is less probable that solutions which potentially disrupt order will be possible without seeming to be an overthrow of the whole set-up. The ordering will be defended at the ultimate cost of the system. Thus with the problems facing us with climate change, the capitalist mode of ordering seems largely incompatible with the necessary innovation to solve the problems. In NSW for example the government may make advertisements full of black 
balloons displaying carbon emissions and asking us to cut electricity usage, while at the same time increasing electricity prices to keep old producers profitable and encouraging more coal mining in agricultural areas and under water tables, so as to fuel more coal fired power and hence more carbon emissions at potential long term ecological cost (SMH 20 March, 2010). The ordering system seems bent on defending itself against aspects of chaotic reality, thus provoking its ultimate disordering and downfall.

\section{Administration is Disruptive}

As Haga and Acocella point out, small amounts of organisation affect the ease with which people do things, and reduces anxiety by seeming to make the world more predictable and replicable. As a result, people assume that the more effort they put into administration then the easier and more predictable the situation becomes and more time they will save (1980, pp. 19, 23). However, diminishing returns appear quickly, and more energy is soon spent organising than is saved through the organisation (ibid, pp. 24-5, 45ff.). It can, for example, easily take more time to file and catalogue everything neatly in a way which is obvious and efficient for every user, than it does to hope that people can find whatever they need by a more random search, or by keeping recently used files in a nearby pile (Abrahamson 2002). There is also a point at which the amount of anxiety generated by the organising exceeds the benefits (which might then prompt further attempts to reduce anxiety by engaging in more ordering). At a later point the organisation can have so many checks, backups and overseers that the amount of time that people spend ordering each other and checking that ordering, leads to paralysis (Haga \& Acocella 1980, pp.54-5).

While demands for measurable outcomes seem beneficial (as we would like to know if things are working), they can also disrupt the organisation's functioning. Measuring the outcomes requires more administrators who thus lower the amount of resources devoted to delivering the services. Demands for accountability can take people away from the work they are supposed to be doing, to work that involves measuring what they should be doing. Then, the measurement tools may not be appropriate for the services offered, and force services into an inappropriate mode. We can focus on cost reduction in hospitals rather than on treating patients.

Measurable outcomes lead to the threat of an organisation or a part of an organisation losing funding or income, if it does not come up to the measures. This might be inherently futile in 
an organisation which is supposed to be creative and inventive, as it removes all recognition of the importance of failure. All attempts at creativity produce dead ends, mistakes and failed attempts. The fact that something is not possible, or some theory does not work, is informative but hard to measure in terms of success. Attempting to measure the success of creativity leads to measures of production and the organisation's members get diverted into producing things which are uncreative or repetitive, as at least this can be counted. In general, most organisations deal with measurable outcomes or dependent funding, by forming committees, possibly hiring external specialists (who don't know how the organisation works) to write applications for more money or to analyse their administration, appointing fact finding task forces, engaging in cost cutting and staff reduction (perhaps hiring more ignorant external advisors at great expense to do this) and so on. This overburdens the actual workers with paperwork, status reports, minutes, insecurity, putting effort into trying to defend their jobs rather than doing them etc. and the organisation can no longer do its business effectively. The result is that it becomes even more subject to the threat of losing income. However everything is highly organised and satisfying to managers who have done the best they can.

This provides an example of Parkinson's law, that 'work expands to fill the time available', which is perhaps a popular throwaway line suggesting that people generate work so they appear useful and worth having. More and more fine detail can be collected and commented upon; more reports produced, and the more time it takes to report on the reports (Parkinson 1958, pp. 4-7). This may not be bad. It provides employment after all, distributing wealth usefully to people who will spend it, and gives their bosses the feeling that they are controlling some hive of activity. It defends people against their bosses, as they are just doing their jobs and organising things ${ }^{7}$. It may also make the organisation resilient, as it has a horde of people familiar with its activities who can be moved to new areas of challenge. Inefficiency is not always bad.

Parkinson adds that 'an official wishes to multiply subordinates not rivals' (1958, p. 5), but there may be more to growth than just expanding one's sense of power and influence. We could also suggest that administration tends to increase, as redundancy demonstrates that you

\footnotetext{
${ }^{7}$ Indeed the more a person's position depends upon others higher up judging their performance, the more they are likely to generate work to be busy and necessary and keep their position.
} 
are administering in the first place. The implicit logic is that if a stronger and repeated message is a clearer message, then more administration is better administration. Rescher suggests that management tends to bloat, not just because mangers appoint underlings, but because the more complex situations become, the more checks, controls and information gathering are required (1998, p.177). In that case, the more efficient information technology is, then the greater the swelling of management. Even governments who claim to want to reduce bureaucracy end up spending more on management, despite the cuts in the services they provide for ordinary people. Indeed, they often try harder and harder to make sure that the benefits are not exploited by the 'lower classes' or 'undesirables’ with ever diminishing returns and increasing costs, but successfully making it harder still for people to obtain any legitimate help. Again, inefficiency can increase the more efficiency is promoted.

Growth in numbers of administrative subordinates can also be beneficial. Semler notes that growth is needed in organisations, especially in business organisations, as growth allows the organisation to diversify and adapt so, if part of it fails, the rest can continue ${ }^{8}$. Growth also provides new opportunities for employees. In a hierarchy, people either strive to be promoted or give up hope of being listened to. As attrition rates rarely equal ambitious hopes, the organisation risks losing people (and possibly trade secrets), or risks people losing their enthusiasm, and so the organisation may create an extra level or two, expanding to satisfy the ambitious and keep itself functional (Semler 1992, pp.263).

More subordinates can also mean deeper bureaucracy, and the deeper the bureaucracy the more that local activities can be kept secret. Obviously this can lead to petty corruption and inefficiency safe from hindrance, but it can also lead to local flexibility, to attempts to adapt to local conditions and to keep the organisation functioning in ways which are not recognised by superiors in the 'centre'. It can solve the problem of innovation when faced with challenging problems to the ordering system, as new solutions can be tried out unofficially and protected from interference by the secrecy provided by layers. These solutions can be discarded if they fail, or distributed (again perhaps secretly) through the system if they work.

\footnotetext{
${ }^{8}$ Imagine a creature with only one skill. If the environment changes so that skill no longer applies, that creature is dead. A creature with more than one skill, or complexities it does not technically need, has a greater chance of finding more than one survival strategy, and hence of surviving. The same is likely for a collection of people with differing skills and views (Page 2007). Redundancy and disorder can be socially and adaptively beneficial as well as inevitable.
} 
A good and functional bureaucracy is not an iron cage but something of a 'mess with procedures'.

However, again it is not simple. As Semler points out, with the increase in staff and levels: soon there is such a pollution of titles and levels - and a diffusion of responsibility and authority that much of management's time is spent dealing with the inevitable conflicts, jealousies and confusion (1992, p.189).

Organisations are often caught between expansion and discontent.

If people do get promoted when they seem competent, then the principle that people tend to get promoted past their level of competence, can take hold (Peter \& Hull 1969). Hindle argues that in 'de-layered' organisations, with much less hierarchy, 'much of the incompetence has disappeared' (2000, pp.171-2), while satirist Scott Adams points out that in 'the old days' the structure of promotion generally meant that a manager had once been competent at something to do with the organisation's purpose. Nowadays they can be imported from outside and thus be promoted 'without ever passing through the temporary competence stage' and having no experience of the work they will be administering (Adams 1996, pp. 12-13). As these particular brought in managers maybe transient, there is also no incentive for them to produce long-term results, only short-term success, which can often be achieved at the reduction of longer-term viability. Contrary to Hindle, there is nothing to suggest that with a low hierarchy, a promotion to incompetence cannot have even more of a widespread bad effect, as there are fewer independent and competing competent modules to keep the organisation functional. The manager may have more, rather than less power over their underlings with no intermediary buffer, thus spreading their incompetence further. Lower hierarchies, especially when key strokes can be traced, imply less separation between the centre and the periphery, and less room for the periphery to move and adapt to local conditions, thus decreasing the ability of organisations to adapt, and increasing the amount of inaccurate information the centre will receive to plan its response. The more inefficiency and redundancy, the more this effect may be countered; the more efficiency the more the effect will disrupt.

Some evidence for promotional incompetence is collected by William Starbuck (1992, Mezias \& Starbuck 2003), who reports research suggesting that the abilities of managers to plan or actually predict the effects of their decisions is quite low; companies with no formal 
strategic planning perform as well as those who do. However, managers involved in planning tend to evaluate their effectiveness and their actions very highly. As already discussed, these managers will get positive feedback from their underlings who know what is expected, and they are therefore fairly ignorant of reality. Starbuck told Abrahamson and Freedman that when 'corporate heads of finance were asked to estimate their companies' sales volumes over the previous five years; $60 \%$ of them couldn't come close', and 'The perceptions of executives are usually terribly wrong... Sometimes it’s truly ludicrous' (Abrahamson and Freedman 2006, pp.43-4). This in itself could be expected to produce disorganisation and anxiety in the workplace as people are driven by the plan, not the reality.

Another explanation for managerial incompetence is that managerial focus is often directed internally to other managers and staff, not externally to the environment or to the people the organisation impinges upon, as that is a requirement of getting on in managerial systems. Resources are allocated throughout an organisation by its administration and administrative structure. The more such resources are distributed internally or the more there is an apparent shortage of these resources, the more the focus of competition will be internal ${ }^{9}$. Therefore, administration has a tendency to be maladaptive to 'externalities', no matter what the kind of organisation is.

\section{The State}

One of the biggest allocators of resources and of defence is the State. The State has an odd ontology. It is clearly not a thing in itself, yet we treat it as such (Radcliffe Brown 1940, p.xxiii; Geertz 2004, particularly the commentary). The State is not necessarily independent of other forces. For example, today, it seems common to argue that the State should be administered like a corporation ${ }^{10}$, even though a corporation has fairly different imperatives, rarely lasts long, and can declare bankruptcy so that all involved can move elsewhere without much hindrance, something a State cannot do. Management techniques appropriate to business may not work elsewhere, and may disrupt the State itself.

\footnotetext{
${ }^{9}$ The internal focus, internal loyalties, or fear of open communication, may reinforce a hidden regime of fraud or recklessness. Vaughan calls this part of the 'dark side of organisations' and remarks that: 'Surprisingly,... harmful actions and the extensive social costs to the public-the dark side of organizations-are not claimed as central to the domain of sociologists who define their specialization as organizations, occupations, and work' (1999, p.272). It could be hypothesised that this learned ignorance results because of our focus on ordering processes rather than on disordering.

${ }^{10}$ IBM's explicit contribution to this discourse can be found at http://www.businessofgovernment.org
} 
Irrespective of how it is administered, by its existence the State creates resources which are limited, such as positions of power, privilege and control over money flows. As a result, conflict is at the heart of the State; both in the relations between people internal to the administration and in their relationships to those defined as potential fellows or outsiders (Elias 1970; Baker 1979, pp.21-3, 41ff., 59). We could define the State as the conceptual locale in which war is continued by, or contained within, largely non-violent means. However, non-violent combat implies recognition, so if this is not granted by one or other of the parties involved then violence can be deployed, with the success of that violence determining its legitimacy and the legitimacy of the winning party. The equation of power with violence is another base of the power/stupidity nexus - the powerful do not have to think about things, they can hit them (Graeber 2004, pp.72-3). However if violence is not equal to the task of imposing consent, then we have civil war which, as a truism, only occurs when there is a State or potential State to be fought over. Hobbes' 'state of nature', the struggle of all against all, requires the State in order to exist.

Over the last three hundred years the Western State has expanded to allow more people to participate. This increased the range of civil society, from nobles and their functionaries, through males with certain amounts of property, to males of non-official religions, to women, to all adults irrespective of property, to making sure minorities have representation.

This expansion caused a great deal of panic amongst those who traditionally controlled the State and there has been some narrowing in effective general participation after the sixties with an increasing influence or dominance of the corporate sector (Marshall 2009). This was an organised solution to the not insignificant problem of getting consensus. The more the State expresses or acknowledges the multiple reflexivities of people and legitimates them, then the more it can be challenged as weak, ineffective and confused. Yet narrowing the State to make it more controllable also appears to fail, both socially and ecologically, because it excises parts of the world, and thus deletes views which do not come from, or do not match those of approved power holders. Sometimes these deletions will occur because of the communicative factors we have discussed above, and sometimes it may be deliberate (see Hamilton \& Maddison 2007; Marr 2007; Shulman 2007). Whatever the case, intensive ordering lowers communication and the possibilities of feedback. 
Attempts to impose an order in favour of business have possibly generated financial crisis and self-destructive behaviour as non-pro-corporate perceptions and knowledges were not included in the State's ambit, and the actions of capitalists could not be curtailed in principle. Bailouts brought about by the failure to listen to warnings about the flaws in the system could be alienating voters and leading to legitimacy crises. So attempts to tighten control may eventually loosen it, or they may eventually lead to the systems destruction (ultimate disorder) if the failed businesses are bailed out, and continue to act in the same manner - that is, to maintain the order they prefer. Despite this apparent increase in control, there is little evidence to suggest that the traditional holders of power feel more secure than they did. If we listen to those who support them in the media, then we hear a constant cry of dismay that their power is so fragmentary. Blame can be put on quite unlikely candidates, creating further ignorance, and leading to further postponement of action, and more attempts to increase control.

If organisation is initially a way of reducing anxiety, then organisation will be applied when anxiety arises. Organisers fear those who are not orderable. If, for example, it is true as Ron Suskind reports that Dick Cheney put forward the idea that "if there is a one percent chance" that someone might do something dreadful to them, then the US Government had to "treat it as a certainty", and that it was "not about our analysis, or finding a preponderance of evidence [but] about our response” (2006, p.62), then this attempt to impose order would not only be never ending, but would lead into wars with little strategic benefit, which might then produce further long-term problems, distrusts and hostilities. Having zero tolerance for disorder could lead to disaster. As suggested by earlier remarks the order of communication imposed by high-level command, meant that confirmatory evidence was found or reported, unclear data was framed in terms of suspicion, and any disconfirmation was ignored.

At a lesser level these kind of fears drive surveillance, which has the potential to further generate terror in the suspect population, and increases their sense of grievance and of not fitting in with the other parts of society, and thus generates some support for the disorderly and perhaps even makes people consider disorder in revenge. Disorder and anxiety is increased and the rights that are supposed to be defended are suppressed.

Fears of the disorders of violence drive the likelihood of violence, or the likelihood of locking down the society's capacity to adapt to the changes which make internal violence more 
likely. The more capacity the State has, the more potential it also has for over-riding dissidents and people who disagree with its actions, and hence the more distrust it generates. If the State could tolerate the idea of disorder then organised, or common, violence could be seen as an indication that something is wrong and might need to be repaired or changed, rather than just suppressed.

However, there is never any guarantee that complete peace and order can be reached at all times. We made need to remember Durkheim's point that crime is normal (and sometimes created by morals, so the more moral and controlled people are the more likely trivial things become violations of those morals) and that therefore 'specialists' in crime will play into the possibilities of violence. Charles Tilly (2003a) implies that the more States attempt to efficiently and effectively police and organise categories, boundaries and exclusions, then the more likely they are to generate groups of people whose identities are based in these exclusions. These groups then provide the basis for violence specialists to put in place the organisation, advance planning, prior training, logistical preparation, and strategic coordination which is required for mass disordering violence, which may then be directed at the State, its 'members' or minority scapegoats who are perceived as being included in the State rather than being with the excluded. Attempts to crack down on the potential violence, also has the possibility of increasing violence by involving people previously on the margins and forcing them into the 'despised' category. Tilly (2003b) also points out that if trust networks grow up outside the State, and we might add the more these are organised, then it is more likely such people will opt out of the State or attempt to exploit it for their own benefit. This may then, we can suppose, impact on ability of their trust networks to survive.

Such factors make it a fundamental, and possibly unsolvable, issue for a State that believes in 'freedom' and 'Rights' as to how it acts towards people within its sway who would overthrow it, or who would claim it is their Right to suppress others. Certainly it would seem impossible to propose a general ordered solution to that problem. Maintaining internal peace is a matter of ongoing struggle, not just attempting to fit people in, but attempting the perhaps impossible task of changing, or relaxing, the order to produce minimal exclusion.

\section{A Step Forward into Useful Disorder?}

In the West and perhaps elsewhere, people have generally called for greater order and efficiency to solve our problems, without considering whether this order will produce further 
disorder, or if disorder may be valuable (even a sign of upwelling creativity). I have discussed some fundamental technologies of order, such as rules, categorisation, communication, law and administration, and have attempted to show the paradoxes that are involved in using them, and how these technologies both enable and restrict. These technologies while helping people to do things, also distort the world they are ordering, they force contrasts and similarities, rather than look at variety. I suggested that those in the Law attempt to deal with these problems through argument, by not assuming that similarity is obvious but that it has to be established, and that even then problems arise. In this sense Justice and Rights are not categories with strict definitions which are always everywhere the same, and attempts to behave as if they were can add confusions and distort reality. They are disordered congeries, which people struggle over with their differing interpretations. The terms may allow us to add the appearance of order, but they are not ordered in themselves.

I have also suggested that good communication is inherently inefficient, and requires some inefficiency and lack of hierarchy in order to work. Furthermore, because of the problems of multiple reflexivities, not only will communication frequently be concerned with strategy rather than accuracy, but predictions about human behaviour will tend to be unstable and selfdefeating. Inclusion and exclusion both create disorder. Similarly, administration, partly because it is concerned with ordering, is plagued with problems of disorder which undermine its efficiency, and this may not be a bad thing in all cases as this inefficiency can further the organisation's chances of survival. People in management may find, that in order to survive as managers, most of their energy has to be directed at an internal environment rather than the environment that the organisation depends upon, so that the organisation may eventually flounder in its internal efficiency. It may also be harmful to translate a successful mode of ordering from one situation to another, as the situations differ and will require different kinds of responses. If ordering produces disorder, and the more so the more rigorous the order, then there are diminishing returns in pursuing order and efficiency.

As a result of these incoherencies there are few, if any, uniform rules for administration. Formalised values crystallise certainty and order, rather than recognise uncertainty and disorder, or the possibility of different situations, different categorisations, change, and struggle, and hence reality itself. There is probably no solution, but I will propose a minimalist position, resembling Popper’s falsification theory of science (Popper 1972, passim). This states that we cannot tell if a proposition or theory is true (as we will always be 
able to find confirmations), however, we should be able to see if it fails. Thus instead of deciding that we know what 'Justice' is, or 'Rights' are, or even what 'Efficiency' is, we can argue over whether a particular decision was unjust, or efficient, or not. There will usually be more agreement about what is unjust than about what is Just, in the same way as there can be more agreement about what is disordered than what is ordered. Thus, while Rights are the only discourse we have to talk about Rights, we will be better served not by attributing Rights in abstract but by objecting to lacks of Rights, by recognising conflict and unresolvability, and by realising Rights are born and maintained in struggle and competition.

Democracy occurs when friction between people is allowed and recognised; when people have the time and place to make objections, to try and slow things down, and to circumvent rules they think are stupid. Inefficiency allows debate and encourages the ordering to adapt responsively to the environment it is both in and creates. Removing institutions such as state governments, local councils, churches, trade unions, business councils, resident's groups etc. removes distributed knowledge of the system and usually seems aimed at removing the frictions facing power so that power can be unimpeded once a decision has been made.

In Australia, the presence of competing civil organisations, levels of bureaucracy, and the three tiers of government mean that governmental bodies have different allegiances, so it is harder for any one group to take over all the machinery, and it provides more institutional space that can be occupied by marginal groups. People can have some hope that their objections against injustice will be heard, rather than just being ignored quickly and efficiently.

There was some effective resistance against John Howard's Government and its apparently totalising plans, because of wasteful state governments. Duplication, although costing more, frequently acts as a check on the power of one organisation, as not everything is done by that one organisation and its masters. The question could be: 'does this extra spending really count as waste when it acts to check total power?' In any case, should we allow some kind of economic judgement to be the only form of judgement that is applied to all possible events, including its own failure? It is doubtful that any one schema can deal with the fact that people want to live differently, and judge the success of events by different schema. Again we hit the problem of an overarching ordering being inherently intolerant and disordering, no matter how inclusive it might want to be. The economic rationalist order wishes to include everyone 
and everything as wage labour or resource - something which perhaps not everyone wishes to be the case - and indeed most economic rationalists probably do not treat their families in that way. In any society there will be competing ideas and concepts about what is order, what order looks like and so on. Thus 'order' may be socially positioned and this is why I have not attempted to define 'order' and 'disorder'; such definitions are a political act.

In decision making the usual path is to seek what we all agree on, and disregard the rest, yet it may be in the discards that the energy lies, and where people have the most enthusiasm. Thus finding the points of agreement may mean that you have an agreement nobody cares about, and cannot actually hold people together. The general blandness of the 2020 reports is a case in point. The initial report stated that:

It is only by having these kinds of conversations that we have any hope of understanding our challenges, their possible solutions, and ultimately each other.

This does not mean we will always agree, and we have disagreed this weekend about many things. Though interestingly, there was a large measure of agreement about many of the major challenges, even if sometimes sharp differences of opinion were evident in discussing solutions. We should not be afraid of disagreement. Indeed an important feature of a liberal democracy is respect for conflicting ideas; difference is part of the human condition (2020 Initial Report, p. 1).

However, there was little if any trace of this disagreement left in that report, which mainly consisted of statements that people would like nice things to happen. It suppressed dissent and fracture for the appearance of a dull uniformity which was expressive of little, and gave little sense of how these nice things would be brought about ${ }^{11}$. The result was that it seems to have been ignored.

An experimental politics recognises that solutions are not known in advance. Politics have to be adjusted; even the best and most reasonable ideas will not always work. Thus we have to allow things to go wrong rather than to cover them up, or assume that if we apply the policies a little more strongly or a little more lengthily they will start to work.

I propose slow, inefficient, government, like slow food. Speed is often confused with efficiency as if when something is faster then it is more responsive; but it can also be less responsive. If, for example, you are driving a car at $200 \mathrm{kph}$ there is less chance of veering to miss if something happens suddenly. Efficiency removes 'room to manoeuvre', 'space which

\footnotetext{
${ }^{11}$ Accounts given to me of the conference by those who attended or who knew people who attended, suggest that some participants actively felt excluded and ignored by this harmonising procedure.
} 
allows a relaxed considered response', 'stored resources' and 'resilience'. As usual, the opposite is also true: moving too slowly can also disrupt. The response, while precise, misses because the events have already moved on. Speed is sometimes needed. There is no easy answer.

However, it would seem to be useful to be aware of two things. Firstly, that all systems of governance, or ordering, are subject to incoherence and will produce disorder; the more efficient and more total the order the more likely it will result in disruptive and destructive disorder. Secondly, it is useful to recognise this incoherence and the possible benefits that arise from allowing disorder and friction, especially if you are in favour of some kind of democracy. Perhaps a society, or State, can only be representative, democratic and inclusive if its members can accept a degree of inefficiency, ambiguity and lack of control?

\section{References}

2020 Initial Report 2008, Initial Summit Report http://www.australia2020.gov.au/docs/2020_Summit_initial_report.pdf

2020 Plenary Stream Report 2008, Plenary Stream Report http://www.australia2020.gov.au/docs/plenary_stream_report_lowres.pdf

Abbott, T.K. 2005, Kant's Critique of Practical Reason and Other Works on the Theory of Ethics 1889, http://oll.libertyfund.org/EBooks/Kant_0212.pdf

Abrahamson, Eric 2002, 'Disorganization Theory and Disorganizational Behavior: Towards an Etiology of Messes', Research in Organizational Behaviour vol.24 pp. 139-80.

Abrahamson, E \& Freedman, D.H. 2006, A Perfect Mess: the Hidden Benefits of Disorder, Weidenfeld \& Nicolson, London.

Adams, Scott 1996, The Dilbert Principle, HarperCollins, New York.

Australia 100 Monday February $4^{\text {th }} 2008$, John August 'Issues Problems and Solutions in State Abolition', http://www.australia100.com/2008/02/issues-problems-and-solutions-in-state.html

Baker, A.J. 1979, Anderson's Social Philosophy, Angus \& Robertson, Sydney.

Bateson, Gregory 1972, Steps to an Ecology of Mind, Chandler Publishing, San Francisco.

Beyerchen, Alan 1992-1993, 'Clausewitz, Nonlinearity, and the Unpredictability of War' International Security, vol.17, no.3, pp. 59-90

Cole, Martin \& Patterson, Greg 2006, Unlocking Public Value: A New Model for Achieving High Performance in Public Service Organizations, John Wiley, Hobokken.

Douglas, Mary 1966, Purity and Danger: An Analysis of Concepts of Pollution and Taboo, Routledge, London.

Eigenauer, J.D. 1993, 'The Humanities and Chaos Theory: A Response to Steenburg's 'Chaos at the Marriage of Heaven and Hell', The Harvard Theological Review, vol.86, no.4, pp.455-469.

Elias, Norbert 1970, 'Process of State Formation and Nation Building', 
http://www.usyd.edu.au/su/social/elias/state.htm

Ferrara, Federico 2003, 'Why Regimes Create Disorder: Hobbes’s Dilemma during a

Rangoon Summer', The Journal of Conflict Resolution, vol.47, no.3, pp.302-325.

Feyerabend, Paul 1999, Conquest of Abundance, Chicago University Press, Chicago.

Geertz, Clifford 2004, 'What Is a State If It Is Not a Sovereign?: Reflections on Politics in Complicated Times', Current Anthropology, vol.45, no.5, pp. 577-93.

Goldsmith, Edward 1973, 'Introduction’ to M.T. Farvar \& J.P. Milton (eds) The Careless Technology: Ecology and International Development, Tom Stacey, London.

Graeber, David 2004, Fragments of an Anarchist Anthropology, Prickly Paradigm Press, Chicago.

Haga, W.J. \& Acocella, N. 1980, Haga's Law: Why Nothing Works and No one can Fix it and the More We Try the Worse it Gets, William Morrow, New York.

Hamilton, C. \& Maddison, S. (eds) 2007, Silencing Dissent: How the Australian Government is controlling public Opinion and Stifling Debate, Allen \& Unwin, Crows Nest.

Hayles, N.K. 1989, 'Chaos as Orderly Disorder: Shifting Ground in Contemporary Literature and Science', New Literary History, vol.20, no.2, pp. 305-322.

Hindle, Tim 2000, The Economist Guide to Management Ideas, Profile Books, London.

King, Preston 1974, Ideology of Order, Allen \& Unwin, London.

Marks, Stephen R. 1974, 'Durkheim's Theory of Anomie', The American Journal of Sociology, vol.80, no.2, pp. 329-363.

Marshall, Jonathan Paul 2002, 'Communication and Conflict', in D. Butt, C. Chesher, G. Fuller, L. Gye, G. Lovink, M. Hankwitz, E. Milne, N. Rossiter and D. Teh (eds), Networks of Excellence, Waikato Institute of Technology and Power Institute of Sydney.

2006, 'Categories, Gender and Online Community’, E-Learning, vol.3 no.2

http://www.wwwords.co.uk/elea/content/pdfs/3/issue3_2.asp\#10

2007, Living on Cybermind: Categories, Communication and Control. Peter Lang, NY.

2009, 'The Physiognomy of Dispersed Power', Leonardo Electronic Almanac vol.16, nos.4-5

http://www.leonardo.info/LEA/DispersiveAnatomies/DA_marshall.pdf

Marshall, Peter 1992, Demanding the Impossible: a History of Anarchism, HarperCollins, London.

Marr, David 2007, 'His Master's Voice: the Corruption of Public Debate Under Howard', Quarterly Essay, no.26.

Merton, R.K. 1936, ‘The Unanticipated Consequences of Purposive Social Action', American Sociological Review, vol.1, no.6, pp.894-904

Mezias, J.M \& Starbuck, W.H. 2003, 'Studying the Accuracy of Manager’s Perceptions: A Research Odyssey’, British Journal of Management vol.14, no.3, pp. 3-17.

Page, S. E. 2007, The Difference: how the Power of Diversity Creates Better Groups, Firms, Schools and Societies, Princeton University Press.

Parkinson, C.N. 1958, Parkinson's Law: or the Pursuit of Progress, John Murray, London.

Peckham, Morse 1979, Explanation and Power, The Seabury Press, NY.

Peter, L.J. \& Hull, R. 1969, The Peter Principle: Why Things Always Go Wrong, Souvenir Press, London.

Popper, K.R. 1972, Objective Knowledge: An Evolutionary Approach, Oxford, University Press.

Proctor, R. \& Schiebinger, L. 2008, Agnotology: The Making and Unmaking of Ignorance, Stanford University Press

Radcliffe-Brown, A.R. 1940, 'Preface', in M. Fortes and E. Evans-Pritchard (eds.), African Political Systems, Oxford University Press. 
Rescher, Nicholas 1998, Complexity: a Philosophical Overview, Transaction Publishers, New Brunswick.

Samuel, Geoffrey 1990, Mind, Body and Culture: Anthropology and the Biological Interface, Cambridge University Press.

Semler, Ricardo 1992, Maverick: The Success Story Behind the World's Most Unusual Workplace, Warner, NY.

Shulman, Seth 2007, Undermining Science: suppression and Distortion in the Bush Administration, $\mathrm{U}$ of California Press.

SMH 10 July 2008, 'Nobble the states: Abbott's quest for power', by Peter Hartcher, http://www.smh.com.au/news/national/nobble-the-states-abbotts-quest-forpower/2008/07/09/1215282927979.html

SMH 13 Sept 2008, 'Abolish state governments, says ousted treasurer', by Alex Tibbitts, http://www.smh.com.au/news/national/abolish-state-governmentscosta/2008/09/13/1220857845923.html

SMH 20 March 2010, 'The Case for Coal Mining is not Entirely Open Cut' http://www.smh.com.au/opinion/editorial/the-case-for-coalmining-is-not-entirely-opencut-20100319-qm26.html

'Why the Utilities want us to use More Power', by Paddy Manning, http://www.smh.com.au/business/why-the-utilities-want-us-to-use-more-power20100319-qm58.html

Starbuck, W. H. 1992, 'Strategizing in the real world', International Journal of Technology Management, vol.8 no.1-2, pp.77-85. [version used from http://pages.stern.nyu.edu/ wstarbuc/mob/strategizg.html

Suskind, Ron 2006, The One Percent Doctrine: Deep Inside America's Pursuit of its Enemies since 9/11. Simon \& Schuster, NY.

Tilly, Charles 2003a, Politics of Collective Violence, Cambridge University Press. 2003b, 'Inequality, Democratization, and De-Democratization', Sociological Theory, vol.21 no.1, pp. 37-43.

Ungar, Sheldon 2003, 'Misplaced Metaphor: a Critical Analysis of the 'Knowledge Society', Canadian Review of Sociology and Anthropology, vol.40 no.3, pp. 331-47.

Vaughan, Diane 1999, 'The Dark Side of Organizations: Mistake, Misconduct, and Disaster' Annual Review of Sociology, vol.25 pp.271-305

Veitch, Scott 2007, Law and Irresponsibility: on the Legitimation of Human Suffering, Routledge-Cavendish, Abingdon.

Whimster, Sam 2004, The Essential Weber: a Reader, Routledge, London.

Wilson, R.A. 1980, The Illuminati Papers, And/Or Press, Berkeley. 